\title{
Regiões transfronteiriças: desafios para o desenvolvimento, cooperação e integração regional
}

Submissão: 18/08/2021

Aceite: 26/09/2021

\author{
Nedisson Gessi ${ }^{1}$ \\ Sérgio Luís Allebrandt ${ }^{2}$ \\ Nelson José Thesing ${ }^{3}$ \\ Melissa Welter Vargas ${ }^{4}$ \\ Magalia Gloger dos Santos Almeida ${ }^{5}$
}

\begin{abstract}
Resumo
A região de fronteira, em especial nas cidades-gêmeas é cenário de interações econômicas, socioculturais e políticas, o que a torna local privilegiado para a promoção de políticas públicas de desenvolvimento, cooperação e integração. Portanto, torna-se necessário fortalecer o debate sobre o processo de ordenamento territorial fronteiriço, por meio de experiências que colaboram para a cooperação transfronteiriça e a valorização das políticas públicas de desenvolvimento e integração. $O$ presente artigo tem como objetivo analisar os desafios para o desenvolvimento, cooperação e integração regional em regiões transfronteiriças, bem como a participação da sociedade nesse contexto, vislumbrando a fronteira na perspectiva do desenvolvimento, cooperação e integração regional. Busca ainda, evidenciar experiências locais de integração e cooperação internacional entre o Brasil e Argentina. Quanto à metodologia, optou-se pela Hermenêutica de Profundidade, uma abordagem interpretativa, inserida no paradigma da teoria social crítica. O estudo evidenciou que as ações, programas, projetos e políticas direcionadas ao território fronteiriço ao longo do tempo vêm passando por alterações de nomes, fusões e divisões, evidenciando a desorganização e a falta de articulação, o que explica a pouca eficácia de tais ações. Em suma, apesar dos avanços nas políticas de integração e uma nova prioridade para as regiões de fronteira, tais ações ainda se mostram incipientes e desarticuladas e com pouca eficácia em termos de integração e cooperação, bem como, baixa participação popular além da falta de uma governança vinculada a um órgão supranacional.
\end{abstract}

Palavras-chave: Políticas públicas; Fronteira; Integração; Cooperação; Participação Cidadã.

\section{Cross-border regions: challenges for regional development, cooperation and integration}

\begin{abstract}
The border region, especially in the twin-cities, is the scenario of economical, sociocultural and political interactions, which makes it a privileged place for the promotion of public policies for development, cooperation and integration. Therefore, it is necessary to strengthen the debate about the border territorial ordering process, through experiences that contribute to cooperation, cross-border and the enhancement of public policies for development and integration. Thus, this article aims to analyze the challenges for development, cooperation and regional integration in cross-border regions, as well as the participation of society in this context, seeing the border into the

${ }^{1}$ Doutorado em Desenvolvimento Regional (UNIJUÍ). Professor na Fundação Educacional Machado de Assis. https://orcid.org/0000-0002-4508-2826 E-mail: nedisson@fema.com.br

2 Doutorado em Desenvolvimento Regional (UNISC). Professor do Programa de Pós-Graduação em Desenvolvimento Regional da Universidade Regional do Noroeste do Estado do Rio Grande do Sul (UNIJUí). https://orcid.org/0000-0002-2590-6226 E-mail: allebr@unijui.edu.br

3 Doutorado em Integração Regional. Professor do Programa de Pós-Graduação em Desenvolvimento Regional da Universidade Regional do Noroeste do Estado do Rio Grande do Sul (UNIJUÍ). https://orcid.org/0000-0001-71230717 E-mail: nelson.thesing@unijui.edu.br

4 Doutoranda no Programa de Pós-Graduação em Desenvolvimento Regional da Universidade Regional do Noroeste do Estado do Rio Grande do Sul (UNIJUí). https://orcid.org/0000-0002-0169-3246

E-mail: melissaweltervargas@gmail.com

5 Doutoranda no Programa de Pós-Graduação em Desenvolvimento Regional da Universidade Regional do Noroeste do Estado do Rio Grande do Sul (UNIJUÍ). https://orcid.org/0000-0002-9314-4016

E-mail: magalia.almeida@sou.unijui.edu.br
\end{abstract}

COLÓQUIO - Revista do Desenvolvimento Regional - Faccat - Taquara/RS - v. 18, n. 4, out./dez. 2021 
perspective of development, cooperation and regional integration. This paper also seeks to highlight local experiences of integration and international cooperation between Brazil and Argentina. Regarding the methodology, we opted for Depth Hermeneutics, an interpretive approach, inserted in the paradigm of critical social theory, and because it constitutes possibilities to reflect everyday social events, in which language is seen as social practice and, therefore, conditioned to the context in which it is produced and, thus, the discourses and practices of everyone in the processes are taken as objects of interpretation and reinterpretation. The study showed that actions, programs, projects and policies directed to the border territory along the time have been undergoing through name changes, mergers, and divisions, evidencing disorganization and lack of articulation, which explains the ineffectiveness of such actions. In short, despite advances in integration policies and a new priority for border regions, such actions are still incipient and disjointed and with little effectiveness in terms of integration and cooperation, as well as low popular participation in addition to the lack of a governance linked to a supranational body.

Keywords: Public policy; Border; Integration; Cooperation; Citizen Participation.

\section{Introdução}

O desenvolvimento em regiões de fronteira torna-se tema de estudo cada vez mais em voga, dado os processos e mecanismos de integração, seja na Europa ou na América do Sul. A região de fronteira, em especial nas cidades-gêmeas, é cenário de interações econômicas, socioculturais e políticas, o que a torna o local privilegiado para a promoção de políticas públicas de desenvolvimento, cooperação e integração. Portanto, é possível perceber a atual necessidade em fortalecer o debate sobre o processo de ordenamento territorial fronteiriço, pelas experiências que colaboram para cooperação transfronteiriças e a valorização das políticas públicas de desenvolvimento e integração.

Pensar na fronteira implica refletir sobre um espaço geográfico, um espaço que marca a divisão política entre estados diferentes, mas que também constitui uma matriz cultural, econômica, histórica e social. A fronteira contém possibilidades de conflitos, mas também de cooperação e constitui um território onde muitas vezes as necessidades locais são negligenciadas pelas necessidades nacionais. Em suma, cada fronteira oferece um cenário onde desafios e oportunidades não param de se combinar e onde um duplo processo cultural é gerado com a permanência de certos componentes tradicionais da cultura de origem e incorporação de elementos e modos de vida do outro, num processo que se caracteriza atualmente de transnacional (FANTIN, 2008).

Sendo assim, a temática do presente estudo visa compreender como se dá a dinâmica de cooperação e integração em regiões transfronteiriças. Dessa forma, o estudo tem como objetivo, analisar os desafios para o desenvolvimento, cooperação e integração regional em regiões transfronteiriças, bem como a participação da sociedade nesse processo, o justifica o presente estudo, especialmente, na elaboração de uma Política Nacional de Ordenamento Territorial no Brasil, onde não há como propor um plano para o território nacional sem considerar a 
conformação dos territórios que estão circunscritos, com destaque para as questões bilaterais e multilaterais como os países vizinhos.

Ressalta-se ainda a crescente importância dada aos estudos que envolvem questões de integração, cooperação, desenvolvimento e as novas dinâmicas de fronteira, que visam compreender as mudanças ocorridas nos territórios de fronteira contemplando os novos usos políticos e econômicos desses territórios e também a participação de novos atores na definição e controle social de políticas públicas que atendam as demandas dos cidadãos fronteiriços.

\section{Metodologia}

Para esse estudo, optou-se pela abordagem interpretativa inserida no paradigma da teoria social crítica, por constituir-se em possibilidade de refletir eventos sociais cotidianos em que a linguagem é vista como prática social e, portanto, condicionada ao contexto em que é produzida; por isso, os discursos e as práticas de todos nos processos são tomados como objetos de interpretação e reinterpretação. Neste sentido, a Hermenêutica de Profundidade (HP), proposta por John B. Thompson (1995), se apresenta como importante conjunto de ferramentas teórico-metodológicas para a pesquisa social, principalmente porque, segundo Veronese e Guareschi (2006, p.87), “o referencial metodológico da HP inclui formas de análise complementares entre si, partes de um processo interpretativo complexo".

Thompson destaca duas correntes da Filosofia Ocidental, no que diz respeito às abordagens, sobre as dificuldades do tema e da interpretação. A primeira tem origem da Hermenêutica Fenomenológica de Husserl, que combina os procedimentos interpretativos com a abordagem fenomenológica. A segunda, tem origem na teoria social crítica, tradição filosófica embasada pelos pensadores Kant, Hegel e Marx e desenvolvida por nomes como Horkheimer, Adorno e Jürgen Habermas. Habermas trata a linguagem em suas construções teóricas, situandoa como uma de muitas dimensões da vida social, estando sujeita a deformações provocadas pelo exercício de poder.

Assim, a Hermenêutica de Profundidade oferece um instrumental eficiente, abrangente e crítico, para abordar os modos e como as formas simbólicas se apresentam na realidade cotidiana, o lugar onde a sociedade efetivamente acontece (MOTTA, 2014). Portanto, a Hermenêutica de Profundidade é uma perspectiva interessante, inovadora, criativa e aberta ao diálogo com outras teorias. Contempla-se assim, a pesquisa bibliográfica, documental e entrevistas em profundidade dos atores envolvidos com o tema do presente estudo. 


\section{Resultados e Discussão}

3.1 Múltiplas faces das fronteiras: políticas públicas e participação cidadã

O debate em torno das múltiplas faces das fronteiras assume nova centralidade. Trata-se de um objeto de elevada complexidade, cuja tematização ultrapassa os "territórios" de disciplinas específicas, situando-se em fronteiras interdisciplinares, com ênfase nas Ciências Humanas e Sociais. Assim as múltiplas faces das fronteiras convivem com uma realidade dinâmica e repleta de conflitos, envolvendo formas, dimensões, processos e particularidades históricas, econômicas, sociais e culturais.

As regiões de fronteira internacional na atualidade, têm se convertido em espaços de múltiplos significados, constituindo, suas cidades, espaços complexos de coexistências, conflitos e permanente processo de transformação de suas relações socioespaciais. A fronteira, exposta aos apelos, demandas e interesses dessas complexas relações da sociedade em rede, torna-se também espaço de múltiplas experiências (lugar do encontro, confronto e trocas de diversas formas de manifestação social, cultural e econômica). Os espaços fronteiriços passam a se constituir como lugares privilegiados da ação do capital global, bem como das iniciativas regionais e locais referentes ao processo de formação e gestão de políticas públicas que atendam as demandas dos cidadãos fronteiriços (CAMPOS, 2015).

Com base nesse contexto, torna-se necessário que a política pública inclua a participação social e a descentralização como elementos cernes na sua gestão, reforçando as relações entre estado e sociedade (FERREIRA, 2011). Acrescentam-se as considerações de Medeiros e Borges (2007), sobre a participação cidadã como instrumento fundamental na análise de políticas públicas.

A participação do cidadão também deve contribuir na implementação das políticas públicas por meio da institucionalização de uma gestão social que possibilita a cogestão e a participação dos cidadãos nas decisões públicas (TENÓRIO; SARAIVA, 2007). Tal gestão deve ser permeada por uma ação política deliberativa, na qual o indivíduo participa decidindo seu destino como pessoa, eleitor, trabalhador ou consumidor; sua autodeterminação se dá pela lógica da democracia e não pela lógica do mercado (PAES de PAULA, 2005).

Furtado (1982) esboçava essa visão sobre a participação da sociedade quando afirmava que a evolução de um território/local ocorre quando os atores conseguem expressar de forma fidedigna as suas inquietudes e os anseios, desenvolvendo uma energia convergente, canalizada de forma a se empenhar na resolução ou minimização dos problemas. Portanto, para o efetivo 
funcionamento da integração e cooperação, é necessário organizar a participação coordenada de múltiplos atores políticos e institucionais situados nos diversos níveis de governo dos diferentes países.

\subsection{A fronteira na perspectiva da integração, cooperação e desenvolvimento regional}

O contexto mundial contemporâneo se caracteriza por uma série de profundas mudanças nos campos científico e tecnológico. Os resultados de tais mudanças impactam fortemente não só nas relações produtivas, mas também nas relações econômicas, políticas e sociais entre os países. Para Preuss (2014), ao final do século XX, evidencia-se uma nova etapa de acumulação do capital, ou seja, uma nova ordem mundial, concentrada no livre mercado, na qual países procuram integrar-se formando blocos econômicos regionais, objetivando a busca de novos mercados e maior competitividade.

Os avanços tecnológicos contribuem para erodir as fronteiras entre mercados até então separados. O resultado dessa erosão é que os Estados não seriam mais "impermeáveis" e passariam a estar sujeitos a novas influências. Se as fronteiras podem ser consideradas uma condição necessária para a implementação de políticas econômicas nacionais independentes, fronteiras mais permeáveis mostram que os Estados estão mais interdependentes. O surgimento de áreas de caráter transnacional, resultantes de interdependência e das novas tecnologias, evidencia que o conjunto de atividades sobre as quais o Estado pode efetivamente exercer seu poder de controle vem diminuindo.

Assim, as fronteiras mais permeáveis significam, também, menos controle de fluxos por parte dos Estados. Seria assim, a incapacidade do 'Estado de regular o fluxo de bens, pessoas, doenças e ideias através dos limites territoriais' que viria sendo descrita como perda de soberania (MATIAS, 2005; PREUSS, 2014). A perda de soberania ou incapacidade do Estado de regular seus fluxos está atrelada ao processo de globalização que, segundo Preuss (2014), com o aprofundamento da internacionalização do capital, o que torna os Estados Nacionais fragilizados, mais enxutos. Assim o Estado-nação perde parte de seu significado tradicional e se obriga a rearticular-se, a reorganizar-se internamente (PREUSS, 2014).

O Estado soberano sempre se relacionou em maior ou menor medida com outros Estados, porém, com a intensificação das relações internacionais, verificou-se uma tendência a que essas relações fossem institucionalizadas. Assim pode-se determinar que se está passando da era da competição para a era da cooperação, ou da integração (MATIAS, 2005; MOREIRA, 2018). 
Portanto, a cooperação internacional pode ser definida como um processo por meio do qual os Estados tornam mais fáceis a realização de seus próprios objetivos pela coordenação de políticas com seus parceiros. Desse modo, é possível constatar que a cooperação internacional deriva da interdependência dos povos e da busca por solução mais eficiente para os problemas mais comuns da humanidade (MATIAS, 2005).

Com base nesse contexto, há um crescimento da cooperação em nível internacional em que se destaca um tipo específico de cooperação entre os Estados: trata-se da integração regional. Em se tratando de integração regional vislumbram-se muitos espaços onde atores diferenciados, sobretudo os Estados, se relacionam e procuram encontrar soluções conjuntas para uma série de problemas ou mesmo tentam propor iniciativas que melhorem as condições econômicas, políticas e sociais de seus territórios a partir da coordenação conjunta de políticas, programas e projetos em espaços de diálogo multilateral (MOREIRA, 2018).

A integração regional é essencialmente um processo de transferência de funções e de lealdades dos Estados para instituições supranacionais, de tal forma que, para o objetivo da integração, os atores sociais e econômicos devem participar ativamente do processo, nele interferindo a partir de determinado ponto após o seu start inicial, buscando pressionar e convencer as elites nacionais a transferirem ou não parcelas de soberania para a esfera regional. Um aspecto importante é a participação, o efeito mobilizador da integração, que por sua vez, está ligado à satisfação do interesse em questão. Essa situação possibilita o aprofundamento e facilita a propagação e manutenção do processo de integração (VIGEVANI et. al., 2008).

Assim, Schmitter (2003), ressalta que a integração regional acontece de fato quando os interesses das principais elites são atendidos. Caso as expectativas desses setores divirjam com a da integração, há nesse sentido um retrocesso, caso contrário surgiria então uma mobilização que daria sustentação ao processo que, em muitos dos casos levam ao surgimento dos chamados blocos econômicos de integração (VIGEVANI, et. al., 2008).

Convém então analisar as razões que levaram os países a se unir em blocos regionais. Em comparação com a cooperação internacional, a integração regional tem algumas características específicas. É possível afirmar que a mesma depende de uma efetiva ligação entre os Estados de uma região com sentido de desenvolvimento de uma comunidade que os tornaria mais próximos entre si do que em relação aos demais Estados. A integração regional também leva os países que dela participam a explorar melhor suas vantagens comparativas, propiciando que busquem tirar proveito da possível complementaridade de suas economias, a fim de concentrar seus esforços nas áreas em que sua produção é mais eficiente. Por conseguinte, a integração regional serve 
para ampliar o espaço competitivo dos países que participam desse processo, permitindo que aumentem sua produtividade, reduzam seus custos e melhorem a qualidade de seus produtos de maneira a inserir-se no mercado globalizado (MATIAS, 2005).

Assim a integração, pode ser entendida como um tipo de cooperação internacional que como já visto anteriormente, é definida como um processo de coordenação política entre os atores interessados em atingir um objetivo comum, sendo assim os Estados ao cooperarem teriam melhores resultados. A diferença entre a cooperação internacional e a integração, é que a integração pressupõe que algumas decisões sejam tomadas no nível supranacional (SANT'ANNA, 2013). Portanto, é de extrema importância o papel do Estado e das políticas públicas como agentes promotores do desenvolvimento, da cooperação, da integração e do ordenamento do espaço e, consequentemente, das fronteiras como uma região de dinâmica própria, complexa e diferenciada em relação a outras regiões do país.

3.3 O papel da fronteira na integração regional: integração e cooperação fronteiriça

As fronteiras políticas entre os Estados apresentam um caráter histórico essencial. Atualmente, o mundo possui 332 mil quilômetros de fronteiras entre Estados (FOUCHER, 2009). Assim, ao longo da história as fronteiras foram se modificando com a criação de novos Estados ou com a sua dissolução até chegarmos a este número atual (Sant'Anna, 2013). Não obstante, as fronteiras exercem papel fundamental para que haja integração, na forma de interação social e cultural entre as sociedades (STEIMAN; MACHADO, 2002).

Recentes alterações geopolíticas têm provocado mudanças no perfil das relações entre os Estados Nacionais, proporcionando maiores oportunidades de integração e cooperação internacional. Tais alterações são mais evidentes no período Pós-Guerra Fria, período esse que foi marcado pela percepção de ameaças mútuas entre os países vizinhos, que para Filho (2004, p. 1) tinha como características: "a instabilidade geopolítica (ameaças de contenciosos fronteiriços e de conflitos territoriais), a predominância de governos autoritários, e a rivalidade acentuada entre países chaves como: Brasil, Argentina e Chile", soma-se ainda a percepção do vizinho enquanto ameaça e a da fronteira enquanto instrumento de separação (FILHO, 2004).

Há algum tempo, existe o debate sobre o papel das fronteiras quanto às questões de integração e cooperação, no contexto das relações internacionais. O processo de formação dos blocos regionais e o advento de novas perspectivas para os países sul-americanos, proporcionaram um novo horizonte pacífico e de respeito mútuo entre os povos da região, 
deixando para trás séculos de desconfiança e disputas (LOSADA; SADECK, 2015). Diante desse contexto, notadamente marcado pela rivalidade e confrontação entre os países da América do Sul, o atual cenário geopolítico é caracterizado por uma forte tendência à integração e cooperação e intenção mútua em suas relações internacionais (FILHO, 2004).

Ainda que as fronteiras se encontrem distantes dos grandes centros, algumas características particulares dos municípios de fronteira devem ser levadas em consideração para a promoção de ações efetivas. Nesse cenário a cooperação fronteiriça deve constituir-se de um conjunto de iniciativas empreendidas pelos dois países em seus territórios de fronteira, pouco povoados e desarticulados entre si com o resto do território de cada país, para dar base ao desenvolvimento e integração futura de tais espaços mediante a execução de ações e projetos que atendam as especificidades desses locais, que pela sua complexidade são diferenciados das demais regiões (MOREIRA, 2018).

Portanto, esse contexto é passível de mudança, primeiramente pela maior importância no cenário contemporâneo que tem sido atribuída às cidades e regiões de fronteira pelos Estados. Em seguida, pela tendência integracionista que tende a reunir os países em blocos, o que poderá transformar essas regiões, futuramente, em zonas de cooperação e sinergia (MOREIRA, 2018).

Segundo Steiman e Machado (2002, p. 6), “a questão das fronteiras internacionais deixou de ser parte do campo estritamente político para integrar o campo econômico". Não somente isso, mas as fronteiras também são locais em que coexistem vários processos de intercâmbio cultural, social e comercial entre as populações que ali habitam.

As fronteiras, mais precisamente entendidas como zonas de contato entre dois domínios territoriais distintos, apresentam um sentido ambíguo, no qual podem considerar-se essas zonas ou regiões, potencialmente, de conflitos; e ao mesmo tempo, lugar de troca entre culturas diferentes (LEMOS; RÜCKERT, 2011). As fronteiras no processo de integração, se encontram nessa dualidade, visto que vivem das diferenças e a integração busca eliminá-las.

Assim sendo, as fronteiras são espaços naturais de interação entre os habitantes o que propicia um passo importante para o aprofundamento da integração entre os países sulamericanos. Para que a integração se efetive é necessário pensar essa região, envolvendo os atores locais, da sociedade, do Estado e do setor econômico, com vistas a criar um ambiente para o crescimento sustentável, bem como, o desenvolvimento econômico e social dessas regiões (MOREIRA, 2018). 
Entretanto, há que lembrar que possíveis dificuldades podem ser enfrentadas quando da execução do processo de integração e cooperação, uma vez que são derivadas de diferenças culturais, de informação, de legislação e de comunicação entre os países. Percebe-se a necessidade de uma autoridade supranacional que possa colaborar para incentivar a cooperação e fomentar a aproximação entre os países (LOSADA; SADECK, 2015). Assim sendo, esse contexto de aproximação dos Estados em prol do desenvolvimento de atividades conjuntas e em detrimento de ações únicas de proteção e segurança das fronteiras nacionais, propiciou uma mudança de postura dos países e deflagrou um ambiente adequado para uma nova ordem mundial (SADECK; BARROS, 2016).

No cenário atual de globalização, as funções das fronteiras passam por transformações a partir de novos usos políticos e econômicos do território, ocorrendo a passagem de um conceito de fronteira-separação para um de fronteira-cooperação (DIETZ, 2008). Nesse sentido, a fronteira passa a ter uma função permeável e articulante. O papel da fronteira é fundamental nesse cenário de globalização, visto que, essa região é o caminho natural por onde podem ser executados programas e projetos de cooperação bilateral ou multilateral, com vistas à aproximação dos países (SADECK; BARROS, 2016).

Mesmo com a possibilidade de uma gama de programas e projetos que visem a integração e cooperação fronteiriça, o que se observa é que a integração já ocorre nas localidades fronteiriças habitadas, muito antes de efetivarem internacionalmente as suas relações com outros Estados. Dessa forma, a integração não é algo novo, o que se constitui como atual é a institucionalização da integração através do reconhecimento dos Estados de que as fronteiras são alguns dos principais canais integracionistas (MENDES; CEOLIN; COLVERO, 2019).

Nesse sentido as questões de institucionalização podem ser o primeiro passo para que a integração fronteiriça se efetive, mas para isso, torna-se necessário a criação de um regime fronteiriço, que contemple uma série de medidas especiais dirigidas à promoção e garantia do desenvolvimento fronteiriço em vários setores. Podem ser citados como exemplos os acordos feitos para o fomento econômico e financeiro; do desenvolvimento social; da educação; de medidas comerciais; do desenvolvimento ambiental e turístico; cultural; e de minas e energia (MOREIRA, 2018).

A fronteira por natureza é um local de intensas e constantes mudanças, em função das necessidades dos povos que lá residem, o que influencia a transformação social. A cooperação fronteiriça procura atender às demandas desses povos em um dado momento, fazendo com que 
o relacionamento entre eles se desenvolva como se não existisse uma divisão ali (ODDONE, 2014).

Para que a integração e cooperação fronteiriça se consolide é necessário: que os territórios compreendidos sejam atores participativos no processo de conectividade física; que possa haver acordo político de alto nível entre os países envolvidos, materializado em algum marco institucional que ordene suas relações; e o reconhecimento da participação dos governos subnacionais fronteiriços, na qualidade de articuladores dos atores locais, como parte institucional necessária para uma governabilidade efetiva (MOREIRA, 2018).

Assim, tanto para a integração quanto para a cooperação fronteiriça, a participação da sociedade civil é um elemento importantíssimo. Por trás de um acordo de cooperação, por exemplo, há uma série de grupos sociais que demandam políticas específicas. Uma vez que o conceito de fronteira adquiriu novos significados, deixando para trás a visão de que o vizinho era inimigo, abriu-se uma série de oportunidades para a resolução de problemas comuns nessas áreas: o de cooperação e de integração regional (OBDONE, 2014). Desse ponto de vista, projetos de cooperação internacional descentralizada podem contribuir de forma a favorecer alianças territoriais e promover a governança multinível em zonas de fronteira.

Sendo assim, o conceito desse tipo de cooperação, inicialmente, pode ser definido como um mecanismo de intercâmbio de conhecimentos e de recursos econômicos, materiais e humanos, entre países que têm como objetivo fomentar o desenvolvimento e onde estados e municípios exercem um papel internacional, por meio de trocas de experiências e boas práticas com parceiros homólogos. Ele permite aprimorar as políticas públicas de governança local, mediante, por exemplo, a apresentação de experiências de práticas bem-sucedidas ou do conhecimento de outras realidades e formas de aplicação de políticas públicas em países vizinhos. Já o conceito de integração regional é uma modalidade de cooperação econômica, técnica, científica, cultural e tecnológica internacional que se dá entre países em desenvolvimento, por meio do compartilhamento de desafios e experiências semelhantes (ODDONE, 2014).

Há casos nos quais as demandas de atores transfronteiriços acabam por não serem supridas, nem pelo processo de globalização, de uma forma geral, nem pelos regionalismos, em menor escala. Essa demora faz com que a integração fronteiriça seja levada com maior impulso político em nível bilateral entre os Estados, de forma que as demandas, tanto de grupos sociais locais quanto de organizações cidadãs públicas ou privadas, acabam por se traduzir no desenvolvimento de experiências informais em cooperação transfronteiriça (MOREIRA, 2018). 
Como mencionado, os Estados Nacionais, sozinhos, não conseguem mais alcançar a capacidade plena da promoção do desenvolvimento, tanto no âmbito nacional como na esfera local, provocando um fenômeno de certa transferência dessa capacidade para as entidades subnacionais. Tais entidades possuem em suas esferas de poder, as mesmas atribuições de um Estado Nacional, principalmente nos modelos federativos (PRADO, 2015).

Entre as principais iniciativas que visam à superação de lacunas nas mais diversas áreas das regiões de fronteira, destacam-se: os Comitês de Fronteira (CFs); a Iniciativa para Integração da Infraestrutura Regional Sul-Americana (IIRSA); o Acordo sobre Localidade Fronteiriça (ALF); o Consórcio Intermunicipal de Fronteira (CIF); o programa de escolas bilíngue de fronteira (PEBIF); o Sistema de Informação de Saúde da Fronteira (SIS-Fronteira) e a Nova Agenda para Cooperação e Desenvolvimento Fronteiriço entre Brasil e Uruguai.

Os Comitês de Fronteira (CFs) binacionais, previstos no Programa de Promoção do Desenvolvimento da Faixa de Fronteira (PDFF), desenhados como fóruns abertos, onde são tratados temas de interesse das populações de fronteira, com o objetivo de promover maior troca de informações, de modo a suprir a escassez de diálogo e buscar de forma conjunta a solução dos problemas locais (MOREIRA, 2018).

A Iniciativa para Integração da Infraestrutura Regional Sul-Americana IIRSA foi lançada em 2000 e constituía-se, naquele momento, em uma proposta de plano de integração da infraestrutura regional com enfoque em transporte, energia e telecomunicações. A IIRSA possui especificidades quanto aos objetivos pretendidos, que refletem o histórico e desdobramentos do regionalismo sul-americano (CARNEIRO FILHO; RÜCKERT, 2015). Há que ressaltar que a instalação de infraestrutura na fronteira, por si só, não constitui fator de cooperação, no entanto, medidas como a construção de uma ponte internacional ou de uma hidrelétrica binacional são importantes para a consolidação da integração regional.

Para além das obras de infraestrutura, a IIRSA constitui uma ferramenta importante para a realização dos objetivos de integração regional nas dimensões política, econômica e social. A iniciativa constitui um marco nas políticas de integração física na América do Sul não apenas por sua magnitude como por seu caráter multissetorial (SCHEIBE, 2013).

Em 2009 a IIRSA foi incorporada ao Conselho Sul-Americano de Infraestrutura e Planejamento (COSIPLAN). O Conselho configura uma instância de discussão política através da consulta, cooperação e planejamento e da coordenação de esforços e articulação de projetos para a implementação da infraestrutura dos países membros da UNASUL. Através da IIRSA- 
COSIPLAN uma série de projetos de integração como pontes e rodovias foram criadas ao longo das fronteiras sul-americanas (SCHEIBE, 2013; CARNEIRO FILHO; RÜCKERT, 2015).

Outros projetos do governo brasileiro para a fronteira, previstos para os próximos anos, são as hidrelétricas de Garabi e Panambi, que serão instaladas no Rio Uruguai, na fronteira BrasilArgentina, e a segunda ponte sobre o Rio Paraná, na fronteira Brasil-Paraguai. Um ponto negativo desses projetos, que se repete com frequência, é a falta de participação das populações fronteiriças que serão impactadas pelas obras. No caso das hidrelétricas de Garabi e Panambi, pequenos municípios do Rio Grande do Sul e de Misiones-ARG deverão ser desalojados pela formação dos reservatórios. Com a negligência dos governos, que não informam nem consultam os habitantes da região, estes reagiram e passaram a organizar manifestações e reuniões nas cidades que serão inundadas, com o apoio do Movimento dos Atingidos por Barragens - MAB (CARNEIRO FILHO; RÜCKERT, 2015).

No que tange aos trabalhadores fronteiriços, a política do Brasil vem se caracterizando pela preferência por acordos bilaterais com os países vizinhos ao invés da adoção de normas e regras aplicáveis a todas as cidades-gêmeas, como destaca Machado (2005, p. 265) "no caso do Brasil, não existe um marco regulatório único para tratar fluxos de trabalhadores transfronteiriços, em geral adotando-se uma política diferente segundo o lugar geográfico, os interesses brasileiros e a relação com o país vizinho".

Em 2005, Brasil e Argentina firmaram o Acordo sobre Localidades Fronteiriças Vinculadas, com o intuito de facilitar a vida da população de dez conjuntos de cidades fronteiriças, através da redução de algumas barreiras burocráticas do Mercosul. O acordo prevê a emissão de uma Carteira de Trânsito Vicinal Fronteiriço, que garante a cidadãos brasileiros e argentinos o direito de frequentar escolas, ocupar postos de trabalho e utilizar o serviço público de saúde no país vizinho (CARNEIRO FILHO, 2013).

O texto do referido acordo foi aprovado pelo Congresso da Argentina através da lei $\mathrm{n}^{\circ}$ 26.523, em 2009. Por sua vez, o Congresso brasileiro, por meio do Decreto Legislativo $n^{\circ} 145$, de 2011, também aprovou o acordo, que foi promulgado pela presidente Dilma Rousseff, em 2016. O texto do documento garante os seguintes direitos aos cidadãos residentes nas cidades vinculadas: a) Exercício de trabalho de acordo com as leis destinadas aos nacionais da parte onde é desenvolvida a atividade, gozando de iguais direitos trabalhistas e previdenciários e cumprindo as mesmas obrigações que delas emanam; b) Acesso ao ensino público em condições de gratuidade e reciprocidade; c) Atendimento médico nos serviços públicos de saúde em condições 
de gratuidade e reciprocidade; d) Acesso ao regime de comércio fronteiriço de mercadorias ou produtos de subsistência, segundo normas específicas.

Na carteira de Trânsito Vicinal Fronteiriço constará o domicílio e as localidades onde o titular estará autorizado a exercer os direitos contemplados no Acordo de Localidades Fronteiriças. O documento terá validade de cinco anos, podendo ser prorrogado por igual período, ao final do qual poderá ser concedido por tempo indeterminado. Há restrições ao cidadão que tenha sofrido condenação criminal ou esteja respondendo processo penal ou inquérito (BRASIL, 2005).

É importante ressaltar que a falta de representação dos atores locais nas políticas de Estado traçadas para a fronteira, bem como a ausência de instituições para instrumentalizar a cooperação entre os cidadãos dos diferentes lados da fronteira, fazem com que essa cooperação acabe se dando informalmente. Esta informalidade acontece por meio de acordos tácitos entre as autoridades locais dos países fronteiriços (CARNEIRO FILHO, 2013).

Em busca do fortalecimento das ações conjuntas dos governos subnacionais, notadamente os municípios, foi criada a Lei no 11.107/2005 que vem complementar e aprimorar o desafio federativo brasileiro que emerge junto da Constituição de 1988. A chamada Lei dos Consórcios Públicos dá nova regulamentação à cooperação horizontal e vertical entre as três esferas de governo para gestão compartilhada de políticas públicas e institui um arcabouço legal e institucional para a concretização do Federalismo Cooperativo no país ((LOSADA; SADECK, 2015).

O Consórcio Público constitui essencialmente um novo instrumento de gestão intergovernamental que possibilita uma maior articulação das iniciativas e políticas públicas entre as diferentes esferas de governo. Contudo o novo instrumento carece de incentivos para a sua efetiva utilização na prestação de serviço público. A instituição de um consórcio público não é tarefa simples, requer todo um processo de debate, articulação e negociação política em torno da definição das cláusulas do contrato de constituição do consórcio, bem como considerar o peso político de cada ente na articulação institucional país ((LOSADA; SADECK, 2015).

O consórcio público, em razão de sua complexidade, é um instrumento capaz de formalizar uma gestão intergovernamental para assumir diversas finalidades e objetivos comuns, em diversas escalas de atuação do poder público. Nesse sentido, o consórcio público responde, assim, à necessidade de uma maior institucionalização da cooperação intergovernamental. 
Uma das principais iniciativas no âmbito da cooperação entre municípios na fronteira Brasil-Argentina é o CIF (Consórcio Intermunicipal da Fronteira) ${ }^{1}$. Em busca de soluções para problemas comuns da região de fronteira, o CIF foi uma alternativa encontrada. Trata-se do primeiro e único consórcio público brasileiro que reúne municípios de estados e países diferentes (LOSADA; SADECK, 2015; ANDREATTA, 2016).

O consórcio é fruto do trabalho realizado pelos prefeitos da região que, por meio de parcerias, desenvolvem ações e projetos para o Desenvolvimento Regional. O CIF tem como metas o gerenciamento e a execução de serviços de construção, conservação e manutenção de vias públicas municipais e de obras públicas; a elaboração de projetos técnicos de engenharia; e a prestação de assessoria na elaboração e execução de planos, projetos e/ou serviços relacionados com os setores sociais, econômico, de infraestrutura e institucionais (notadamente: educação, saúde, trabalho, ação social, habitação, saneamento, agricultura, indústria, comércio, turismo, abastecimento, transporte, comunicação, meio ambiente, aterro sanitário, emprego e renda, esportes, cultura e segurança) (CARNEIRO FILHO, 2013).

Também é objetivo do CIF articular os municípios consorciados na defesa dos seus interesses face às esferas estaduais e federal, além de conceber e gerenciar uma central para os municípios consorciados adquirirem bens e serviços comuns. Entre as ações realizadas de forma integrada entre os municípios de Barracão-PR, Bom Jesus do Sul-PR, Dionísio Cerqueira-SC e Bernardo de Irigoyen (ARG), destacam-se o Parque Turístico Ambiental, a Patrulha Mecanizada e o transporte de pacientes etc. (CIF, 2020).

O consórcio já conseguiu realizar ações e algumas ainda em execução, melhorando o cenário da região e permitindo o desenvolvimento contínuo e próspero dessa faixa de fronteira. Entre as ações desenvolvidas, destaca-se a elaboração do Plano Plurianual Participativo do Território. O CIF já é referência tanto no país como também no âmbito do Mercosul, visto que é a única iniciativa exitosa do gênero, um arranjo territorial que tem se mostrado extremamente eficaz para atração de investimentos públicos e privados (LOSADA; SADECK, 2015; ANDREATTA, 2016).

A experiência do CIF tem mostrado que a integração e cooperação fronteiriça são o meio de dinamizar o processo de desenvolvimento econômico e social dessas regiões de fronteira. 0 grande desafio é responder à especificidade dessa região, que exige criar políticas públicas e

\footnotetext{
${ }^{1}$ Criado em 2009, o CIF foi constituído sob a forma de associação pública com personalidade jurídica de direito público e natureza autárquica, regendo-se pelos dispositivos da Constituição Federal de 1988. Seus membros são os municípios de Barracão-PR, Bom Jesus do Sul-PR e Dionísio Cerqueira-SC.
} 
legislação que atendam a realidade desses locais, com propósito de resolver problemas comuns das cidades-gêmeas e demais municípios próximos, localizados na faixa de fronteira.

Os projetos no campo da educação são em muitos casos um fator facilitador da cooperação transfronteiriça. Ao longo da fronteira brasileira há diversos exemplos de cooperação promovidos através do intercâmbio de professores e alunos. Em 2010, o governo brasileiro, através da lei 12.189 , criou a Universidade Federal da Integração Latino-Americana (UNILA), com sede na cidade de Foz do Iguaçu. A nova universidade nasceu com o objetivo de formar recursos humanos aptos a contribuir com a integração latino-americana, o desenvolvimento regional e o intercâmbio cultural, científico e educacional da América Latina (CARNEIRO FILHO, 2013).

A UNILA foi idealizada com a meta de ter $50 \%$ de seus corpos discente e docente compostos por estrangeiros latino-americanos. Em maio de 2013, o percentual de estudantes estrangeiros se aproximava de $50 \%$ do total de discentes. Um ponto em prol da integração, que merece ser destacado, é que todos os alunos estrangeiros que comprovam necessidade situação de baixa renda familiar- recebem bolsa de estudos (CARNEIRO FILHO, 2013).

Em poucos anos de existência, a UNILA tem se destacado pela parceria em iniciativas de cooperação transfronteiriça. Neste sentido, a instituição possui uma parceria com o CIF no âmbito da promoção de cursos superiores e atividades acadêmicas de pesquisa e extensão, além de oferecer assessoria técnica aos municípios do consórcio (UNILA, 2020). A UNILA também está presente no Projeto Escola Intercultural Bilíngue de Fronteira (PEIBF). Criado em 2005, através de um acordo entre Brasil e Argentina, o projeto foi ampliado e hoje promove o intercâmbio entre professores de cidades fronteiriças dos países do Mercosul (UNILA, 2020).

O Programa Escolas Bilíngues de Fronteira nasceu da necessidade de estreitar laços de interculturalidade entre cidades vizinhas de países que fazem fronteira com o Brasil. Buscando mudar de forma radical as relações entre o Brasil e a Argentina, de acordo com o Ministério da Educação, ressalta-se que o programa se propunha então a desenvolver uma cultura de paz, colaboração interfronteiriça através da construção de uma cidadania regional, intercultural e bilíngue (BARBOSA; PISETTA, 2019). O objetivo principal do Projeto Escola Intercultural Bilíngue de Fronteira é a integração de estudantes e professores brasileiros com os alunos e professores dos países vizinhos. O foco é a integração, a quebra de fronteira, além da ampliação das oportunidades do aprendizado da segunda língua (BRASIL, 2008).

Sobre as políticas públicas do governo federal brasileiro para melhorar a situação de saúde das localidades fronteiriças, em 2005 o governo implantou um projeto conhecido como 
Sistema de Informação de Saúde da Fronteira (SIS-Fronteira) que esteve vigente até 2014. O objetivo desse projeto era ampliar a capacidade de atendimento de 121 municípios localizados em até 10 quilômetros da linha de fronteira, através de um sistema de compensação financeira, uma vez que a população itinerante não era contabilizada para fins de repasse financeiro do governo federal (HORTELAN, 2019).

No contexto brasileiro, o programa governamental relatado nos estudos foi o SISFronteira, uma das soluções encontradas pelo Brasil para resolver o problema da população fronteiriça. Trata-se de um programa exclusivamente nacional sem ajuda dos países vizinhos e delimitação do papel do gestor em saúde. Portanto, acordos binacionais, cidadania de estrangeiros e programas/políticas dirigentes sobre atendimento aos transfronteiriços são maneiras de melhorar a efetividade dos serviços de saúde, construir e direcionar o papel do gestor de saúde pública na região de saúde pública (HORTELAN, 2019).

E por fim, outra experiência é o caso da Nova Agenda para a Cooperação e Desenvolvimento Fronteiriço entre Brasil e Uruguai. A Nova Agenda constitui-se na mais alta instância para cooperação e integração fronteiriça que tem sua origem nas demandas da região de fronteira entre Brasil e Uruguai. Questões como o contrabando, a ilegalidade de trabalhadores, estudantes e cidadãos, e atendimento hospitalar nos dois lados da fronteira se impõem sobre a região, demandando ações das autoridades (LEMOS; RÜCKERT, 2014).

A criação dos Comitês de Fronteira, em 1989, foi a primeira iniciativa no sentido de favorecer o diálogo das populações fronteiriças com os órgãos centrais do Estado, sendo anterior à Nova Agenda e objetivando favorecer a cooperação e o desenvolvimento na faixa de fronteira entre as cidades-gêmeas. Durante a década de 1990, os Comitês de Fronteira foram perdendo o fôlego, espaçando cada vez mais suas reuniões devido à pouca capacidade desses órgãos auferirem resultados concretos (AVEIRO, 2006). Com o desenvolvimento do programa da "Nova Agenda", os Comitês de Fronteira ganharam novo alento, tendo o papel de canal de comunicação entre as comunidades locais e as esferas de poder (LEMOS; RÜCKERT, 2014). Assim, destaca-se: a) O Acordo para Permissão de Residência, Estudo e Trabalho a Nacionais Fronteiriços Brasileiros e Uruguaios. Tal acordo prescreve os parâmetros para habitantes de Sant'Ana do Livramento e Rivera - e também de outras dez cidades-gêmeas brasileiras e uruguaias - residirem, exercerem profissão ou ofício com direitos previdenciários e frequentarem estabelecimentos de ensino público e/ou privado, situados no território de qualquer uma das partes; 
b) O ajuste complementar ao Acordo para Permissão de Residência, Estudo e Trabalho para Prestação de Serviços de Saúde visa a permitir a prestação de serviços de saúde humana por pessoas físicas ou jurídicas situadas nas localidades estabelecidas no próprio acordo;

c) Acordo para Criação de Escolas e/ou Institutos Binacionais Fronteiriços Profissionais e/ou Técnicos e para o Credenciamento de Cursos Técnicos Bi fronteiriços onde o acordo definiu que as escolas e institutos deveriam funcionar da seguinte forma: os postulantes terão $50 \%$ das vagas reservadas para cada uma das partes, sendo que as vagas não preenchidas seriam postas à disposição de qualquer um dos países; em relação ao idioma, os professores poderiam ministrar os cursos na língua materna deles;

d) O Acordo sobre Cooperação Policial em Matéria de Investigação, Prevenção e Controle de Fatos Delituosos no qual prevê o intercâmbio de informações entre as autoridades policiais de ambos os países e a possibilidade de as autoridades ingressarem no território de qualquer uma das partes para requerer, à autoridade policial mais próxima, o procedimento legal correspondente, quando da perseguição a delinquentes. Ele permite uma ação ágil e integrada das autoridades brasileiras e uruguaias;

e) Uma das áreas na qual a cooperação entre as duas cidades está mais desenvolvida é a da saúde. Na região de Sant'Ana do Livramento-Rivera, a cooperação binacional na área da saúde se iniciou com a prevenção à dengue, incentivada pelos Comitês de Fronteira na área da saúde. Pacientes das duas nacionalidades são atendidos na esfera pública e privada, no Brasil e no Uruguai, resultado de uma ação local que tem suas origens em uma política de cooperação binacional. A implementação do Acordo para Permissão de Residência, Estudo e Trabalho a Nacionais Fronteiriços Brasileiros e Uruguaios foi o primeiro passo para a efetiva cooperação local na área da saúde, pois a condição de cidadão fronteiriço possibilita o atendimento em ambos os lados da fronteira (LEMOS; RÜCKERT, 2014).

Na Nova Agenda para Cooperação e Desenvolvimento Fronteiriço entre Brasil e Uruguai, os atores das escalas nacional e local são predominantes. Isso conduziu as regiões a um maior protagonismo, reforçando a necessidade de políticas territoriais que envolvessem atores multiescalares para a consecução dos objetivos delineados e, igualmente, o aperfeiçoamento das respostas das instituições políticas às demandas da sociedade civil. A Nova Agenda para Cooperação e Desenvolvimento Fronteiriço entre Brasil e Uruguai representa, desse modo, uma adequação dos dois Estados à realidade de integração local da fronteira brasileiro-uruguaia. 


\subsection{Experiências locais brasileiras e argentinas iniciativas e ações de cooperação e integração}

Se por um lado as fronteiras ganham novas funções, tornando-se mais porosas e permitindo uma maior agilidade no fluxo de pessoas e mercadorias, por outro, ainda preservam muitos dos seus problemas históricos e encontram-se, muitas vezes, excluídas dos processos decisórios. O centro das decisões muitas vezes se localiza distante da fronteira e as populações nem sempre se encontram bem representadas para defesa das demandas fronteiriças.

Entre as características que predominam nas regiões fronteiriças entre o Brasil e a Argentina, está o baixo nível de desenvolvimento, baixa densidade populacional, baixos indicadores socioeconômicos, tendência a pouca diversidade produtiva e forte dependência em relação aos grandes centros de decisão (DIETZ, 2008). Sendo assim, é possível perceber a atual necessidade em fortalecer o debate sobre o processo de ordenamento territorial fronteiriço, por meio de experiências que colaboram para cooperação transfronteiriça e a valorização das políticas públicas de desenvolvimento, cooperação e integração.

Optou-se em escolher o caso da fronteira envolvendo as cidades-gêmeas de São Borja e Santo Tomé como experiência local de cooperação e integração, por meio de iniciativas da sociedade civil e dos poderes constituídos dessas duas localidades situadas na fronteira entre o Brasil e a Argentina. A metodologia utilizada foi a da Hermenêutica de Profundidade (HP), proposta por John B. Thompson, por ser uma abordagem interpretativa inserida no paradigma da teoria social crítica.

$\mathrm{Na}$ busca de soluções para problemas comuns entre as cidades de São Borja/ Brasil e Santo Tomé/Argentina, destaca-se duas experiências locais evolvendo as atuações da Câmara Binacional, da Associação de Produtores e Empresários São Borja e Santo Tomé (APESS) e do Comitê de Fronteira de Localidade Fronteiriça Vinculada. Para Sabedra (2016) o marco histórico das duas cidades resultou de um processo de expansão histórico-político, promovido pela coroa da Espanha em conjunto com as Companhias de Jesus no século XVII. Assim é possível verificar uma forte correlação e proximidade histórica entre as duas localidades, sendo até mesmo semelhantes às suas formações culturais e localização geopolítica. Vale destacar também o Rio Uruguai, que é fator-chave no processo de integração, pois foi pelo rio que foram realizadas transações comerciais, fluxo de pessoas, entre outras.

Em conformidade com o Estatuto de Fundação, a APESS tem como objetivo, permitir e incentivar as associações a resolverem os problemas decorrentes dos tratados entre os dois países para que estes se integrem, viabilizar condições para a integração argentino-brasileira 
para que possam se desenvolver, além de promover a integração econômica, comercial, social e cultural, com a finalidade de beneficiar ambas as comunidades fronteiriças, segundo Estatuto APESS (1986).

A APESS teve sua criação em meio ao cenário de integração, onde sua atuação mais marcante foi a luta pela construção da ponte internacional que liga São Borja a Santo Tomé. A associação buscou unir todos os setores locais, da economia, produção primária, comércio e indústria na esfera municipal, além de sindicatos, empresários e cooperativas. Assim, com o engajamento das populações fronteiriças é que o sonho da ponte se concretizou.

Atualmente a APESS continua em atividade e, conjuntamente, vem buscando sanar problemas comuns entre as duas cidades-gêmeas. Um dos assuntos em voga diz respeito ao complexo hidrelétrico Garabi-Panambi, envolvendo questões relativas aos impactos socioambientais que podem ser gerados em função da realização da obra, que se encontra em fase de realização de estudos, projetos de engenharia e impactos socioambientais. Portanto, a APESS se mostra como uma entidade de grande relevância nos cenários da integração e cooperação transfronteiriça, tendo contribuído para construção da ponte e, agora, estando envolvida com as questões do complexo hidrelétrico Garabi-Panambi, sempre com o intuito de buscar o desenvolvimento local e regional. Em detrimento à construção da ponte, foi criada a Câmara Binacional São Borja - Santo Tomé, tal entidade é composta por representantes do legislativo das cidades-gêmeas. A criação da entidade visa discutir e deliberar sobre temas diversos de comum interesse. Dessa forma, a Câmara Binacional juntamente com a APESS teve relevante contribuição para a construção da ponte internacional. Uma das ações pleiteadas pela Câmara Binacional foi a de requerer a permanência da Delegacia da Polícia Rodoviária Federal em São Borja, se opondo assim, à unificação com a Delegacia de Uruguaiana, visto que o interesse era a importância estratégica da localização do órgão. Outra ação, foi a proposta de uma moção de apoio ao projeto denominado Corredor do Mercosul que visa possibilitar a maior integração econômica entre esses países, especialmente Brasil, Argentina, Paraguai e Bolívia.

Segundo Sabedra (2016), o trabalho das duas entidades passa a ser reforçado com o advento do Decreto no. 8636/2016, que promulga o Acordo entre a República Federativa do Brasil e a República Argentina sobre localidades fronteiriças vinculadas, através do qual é instituído o Comitê de Fronteira. A Câmara Binacional e a APESS permanecem atuantes em benefício dos interesses fronteiriços e na constante busca pela integração. Entretanto, no tocante às tratativas do Decreto, fica a responsabilidade para o Comitê de Fronteira de Localidade Fronteiriça Vinculada, que será tratado a seguir. 
O acordo entre a República Federativa do Brasil e a República Argentina sobre Localidades Fronteiriças Vinculadas, firmado em Puerto Iguazú, na Argentina em 2005, constitui mais uma ação realizada pelos governos centrais na tentativa de promover a integração entre as comunidades fronteiriças envolvidas. Dessa forma, o ato bilateral tem como objetivo fortalecer a integração entre os municípios fronteiriços, sendo que a população restará beneficiada com serviços como saúde, trabalho e educação.

As localidades vinculadas beneficiadas são: Foz do Iguaçu - Puerto Iguazú; Capanema Andresito; Barracão/Dionísio Cerqueira - Bernardo de Irigoyen; Porto Mauá - Alba Posse; Porto Xavier - San Javier; São Borja - Santo Tomé; Itaqui - Alvear; Uruguaiana - Paso de los Libres; e Barra do Quaraí - Monte Caseros. Está prevista ainda, a criação de uma Carteira de Trânsito Vicinal Fronteiriço, que dará aos portadores o acesso a serviços e direitos no país lindeiro estabelecido pelo acordo, tais como o exercício de trabalho, acesso ao ensino público e ao regime de comércio, como também o atendimento médico nos serviços públicos com iguais condições aos domiciliados nacionais (BRASIL, Decreto n. 8.636, art. III 2016).

Pelo Decreto n. 8.636/2016 foi instaurado o Comitê de Fronteira de Localidade Fronteiriça Vinculada, criação efetivada no dia 25 de fevereiro de 2016. Preliminarmente, o Comitê é composto pelos prefeitos de São Borja e Santo Tomé, os presidentes do Legislativo e os secretários de Relações Internacionais dos dois municípios, assim como dois assessores legais. Fica o Comitê de Fronteira de Localidade Fronteiriça Vinculada responsável sobre os temas que versam sobre o Decreto n. 8.636/2016 e demais temas correlatos, segundo Câmara de Vereadores de São Borja (2016).

A atuação das três entidades tem se mostrado importante nas questões, com ênfase em experiências locais na busca conjunta em resoluções de problemas que acabam por se tornar de magnitude internacional. No entanto, como resultado, a conjuntura apresentada configura-se como insuficiente para que se tenha uma efetiva integração, tendo em vista que a maior parte das temáticas discutidas envolve competências legislativas e administrativas no âmbito dos poderes centrais de cada país. Sendo assim, até o presente momento, pouco se teve de alterações concretas para as populações da zona de fronteira. Dentre as pautas discutidas destacam-se o desenvolvimento regional, o Mercosul, a obra binacional do complexo de GarabiPanambi e temas de ordem das Localidades Fronteiriças Vinculadas com adesão e interesse por parte dos municípios da região de fronteira. 


\section{Considerações Finais}

A região de fronteira vem passando por importantes transformações deixando progressivamente de ser concebida como uma região-problema, passando a se constituir em uma região prioritária e estratégica para o desenvolvimento regional. Na prática, mesmo que as ações sejam ainda insuficientes, as políticas públicas locais para essas regiões tornam-se cada vez mais importantes. Nesse sentido a representatividade da fronteira está inserida dentro de um parâmetro de políticas de integração, que são traduzidas também em termos de demandas sociais e que podem determinar alterações na relação entre os processos de governabilidade e formas concretas de vivência daquelas populações.

A região de fronteira torna-se uma importante diretriz da política nacional e internacional, principalmente porque a vasta extensão territorial de $150 \mathrm{~km}$ de largura ao longo de $15.719 \mathrm{~km}$ da fronteira brasileira, na qual abrange 11 unidades da Federação e 588 municípios divididos em sub-regiões, reúne aproximadamente 10 milhões de habitantes, permite ao Brasil estabelecer fronteira com quase todos os países da América do Sul, o que configura possibilidades e especificidades regionais, e, consequentemente, impossibilita ações padronizadas, ao passo que potencializam perspectivas de atuação para a viabilização da integração sul-americana.

Optou-se por escolher como recorte do presente estudo, a fronteira entre o Brasil e a Argentina em face da expressiva extensão de suas fronteiras e, sobretudo, pelas funções que desempenham no cenário de integração regional, adquirindo grande relevância. Para Dietz (2008) estas unidades federativas possuem uma importância histórica no que se refere à configuração de suas fronteiras e, por consequência, na construção das fronteiras nacionais, considerando que nessa região ocorreram os maiores conflitos e disputas para a delimitação territorial dos países da Bacia do Prata. Além disso, é nessa porção que há o maior número de cidades-gêmeas e que apresentam características mais dinâmicas da América do Sul.

Ressalta-se ainda, a crescente importância dada aos estudos que envolvem questões de integração/cooperação, desenvolvimento e as novas dinâmicas de fronteira, que visam compreender as mudanças ocorridas nos territórios de fronteira, contemplando os novos usos políticos e econômicos desses territórios e também a participação de novos atores na definição e controle social de políticas públicas que atendam as demandas dos cidadãos fronteiriços.

Destaca-se que a integração regional tem proporcionado uma dinâmica que outorga aos territórios de fronteira uma prioridade antes não conhecida, na definição de políticas públicas e exigindo estratégias de cooperação com intervenção de diversos atores em diversas escalas. 
Nesse sentido, a região de fronteira se constitui em um espaço de integração entre atores institucionais e organizações sociais que se fundamentam em ações compartilhadas. Observamse avanços nas políticas de integração e uma nova prioridade para as regiões de fronteira, mas ainda se mostram incipientes e desarticuladas as ações de integração e cooperação, com baixa participação popular e a falta de uma governança vinculada a um órgão supranacional.

O desenvolvimento de estudos dessa natureza busca fornecer subsídios para melhoria dos instrumentos de planejamento e gestão de políticas públicas nas regiões transfronteiriças, adequados aos processos de gestão do desenvolvimento local e regional, bem como, servir de suporte para a reformulação das políticas de desenvolvimento, cooperação e integração.

Por fim, com esse estudo busca-se contribuir para a contenda teórica e prática acerca da dinâmica de formação e gestão das políticas públicas de desenvolvimento, cooperação, integração e a participação da sociedade civil nos espaços de deliberação e controle social na região transfronteiriça entre o Brasil e a Argentina, bem como, fornecer subsídios para a melhoria dos instrumentos de planejamento e gestão de políticas públicas nas regiões transfronteiriças, adequados aos processos de gestão do desenvolvimento local e regional.

\section{Referências}

ABINZANO, R. C. Procesos Transnacionales en las regiones de frontera: la Triple Frontera en el sistema mundo. Revista Idéias: Etnografias do Capitalismo contemporâneo revisitado.

Campinas, São Paulo: Universidade Estadual, v.5 n. 2, 2014.

ANDREATTA, A. Cooperação Transfronteiriça e Integração Regional o Consórcio Intermunicipal da Fronteira. Dissertação apresentada ao Curso de Pós-Graduação em Integração Contemporânea da América Latina, da Universidade Federal da Integração Latino-Americana. Foz do Iguaçu, 2016.

AVEIRO, T. M. M. Relações Brasil-Uruguai: A Nova Agenda para a Cooperação e o Desenvolvimento Fronteiriço. Brasília: UNB, 2006.

BRASIL. Ministério da Integração Nacional. Secretaria de Programas Regionais. Programa de Desenvolvimento da Faixa de Fronteira. Proposta de Reestruturação do Programa de

Desenvolvimento da Faixa de Fronteira. Ministério da Integração Nacional, Secretaria de Programas Regionais, Programa de Desenvolvimento da Faixa de Fronteira - Brasília: Ministério da Integração Nacional, 2005.

BRASIL. Grupo de Trabalho Interfederativo de Integração Fronteiriça. Bases para uma proposta de desenvolvimento e integração da faixa de fronteira. In: REUNIÃO DO GRUPO DE TRABALHO INTERFEDERATIVO DE INTEGRAÇÃO FRONTEIRIÇA, 5., 2010, Brasília. Relatórios... Brasília: Kaco Gráfica, 2010.

BRASIL, Decreto n. 8.636, de 13 de janeiro de 2016. Promulga o Acordo entre a República Federativa do Brasil e a República Argentina sobre Localidades Fronteiriças Vinculadas, firmado em Puerto Iguazú, em 30 de novembro de 2005. Brasília, DF, 2016. Disponível em: 
https://www.planalto.gov.br/ccivil_03/_ato2015-2018/2016/decreto/d8636.htm. Acesso em jun.2021.

BRASIL, Ministério da Educação. Projeto Escola Intercultural Bilíngue de Fronteira (PEIBF). Brasília: DF, 2008. Disponível em: http://portal.mec.gov.br/escola-de-fronteira/>. Acesso em: jun.2021.

CÂMARA DOS VEREADORES DE SÃO BORJA. Criado o Comitê de Fronteira de Localidade Fronteiriça Vinculada, 2016. Disponível em:

http://www.camarasaoborja.rs.gov.br/noticia.php?id_not=2700. Acesso em: jun. 2021.

CAMPOS, H. A. Cidades em Fronteira: Discussão sobre seus Múltiplos Significados. I Colóquio internacional de História cultura da cidade. Porto Alegre, 2015.

CARNEIRO FILHO, C. P. Processos de Transfronteirização na Bacia do Prata: a Tríplice Fronteira Brasil-Argentina-Paraguai. Porto Alegre, 2013.

CIF, Consórcio Intermunicipal da Fronteira. Disponível em <http://cifronteira.com.br/>. Acesso em: 18/04/2020.

DIETZ, I. C. Cenários Contemporâneos da Fronteira Brasil-Argentina: Infraestrutura estratégica e o papel dos atores no processo de cooperação/integração transfronteiriça. Dissertação. Porto Alegre: UFRGS/PPGEA, 2008.

ESTATUTO APESS. Estatuto da Associação de Produtores e Empresários de São Borja e Santo Tomé (APESS), 1986.

FANTIN, M. A. Población, sociedad y salud en la frontera argentino-paraguaya. Asunción Paraguay: Asociación Paraguaya de Estudios de Población, 2008.

FERREIRA, P. A. Gestão De Políticas Públicas: Uma proposta de Modelo Processual de Análise. Tese apresentada à Universidade Federal de Lavras como parte das exigências do Programa de Pós-Graduação em Administração, área de concentração em Gestão Social, Ambiente e Desenvolvimento. Lavras, 2011.

FILHO, O. M. Da confrontação à cooperação: as alterações geopolíticas na América do Sul. Texto integrante dos Anais do XVII Encontro Regional de História - O lugar da História. ANPUH/SPUNICAMP. Campinas, 2004.

FOUCHER, M. Obsessão por fronteiras. São Paulo: Radical Livros, 2009.

FURTADO, C. A Nova Dependência. 3o edição. São Paulo: Paz e Terra, 1982.

HORTELAN, M. dos S. Papel do gestor de saúde pública em região de fronteira: scoping review. Acta Paulista de Enfermagem. v.32, n.2, São Paulo, mar./Apr., 2019.

LEMOS, B. de O.; RÜCKERT, A. A. A região transfronteiriça Sant'Ana do Livramento-Riveira: cenários contemporâneos de integração/cooperação. Revista de Geopolítica, Natal - RN, v. 2, n. 2, p. $49-64$, jul./dez., 2011.

LEMOS, B. de O.; RÜCKERT, A. A. A Nova Agenda para Cooperação e Desenvolvimento

Fronteiriço entre Brasil e Uruguai: repercussões territoriais nas cidades-gêmeas de Sant'Ana do Livramento e Rivera. Revista Política e Planejamento Regional (PPR), Rio de Janeiro, v. 1, n. 1, p. 138-158, jan./jun., 2014.

LOSADA, P. R.; SADECK, B. R. V. O papel da Fronteira na Integração Regional: o caso do consórcio intermunicipal da fronteira. In: PRADO, H. S. de.; NETO, T. E. (Org.) Fronteiras e relações internacionais. Curitiba: Ithala, 2015. 
MACHADO, Lia Osório. Estado, territorialidade, redes: cidades-gêmeas na zona de fronteira sulamericana. In: SILVEIRA, M. L. (Org.). Continente em chamas: globalização e territórios na América Latina. Rio de janeiro: civilização brasileira, 2005.

MATIAS, E. F. P. A humanidade e suas fronteiras: do Estado soberano à sociedade global. São Paulo: Paz e Terra, 2005.

MEDEIROS, J. P. de; BORGES, D. F. Participação cidadã no planejamento das ações da EMATERRN. Revista de Administração Pública, Rio de Janeiro, v. 41, n. 1, p. 63-81, jan./fev., 2007.

MENDES, L. Z.; CEOLIN, L. P. S.; COLVERO, R. B. Relações intermunicipais de fronteira: análise dos mecanismos de integração adotados pelas cidades-gêmeas de São Borja (Brasil) e Santo Tomé (Argentina). Diálogo, Canoas, n.40, abr., 2019.

MOREIRA, P. G. Trajetórias Conceituais e Novas Formas de Interação nas Fronteiras Brasileiras. In: Bolívar Pêgo (Org.) ... [et al.]. Fronteiras do Brasil: uma avaliação de política pública. Rio de Janeiro: Ipea, MI, v. 1, 2018.

MOTTA, D. A. A Hermenêutica de Profundidade como instrumental de pesquisa qualitativa em Ciências Sociais: uma introdução. In: XVI Congresso Brasileiro de Sociologia, 2013, Salvador/BA. Livro de Resumos. Salvador/BA: Sociedade Brasileira de Sociologia - SBS. p. 203203, 2014.

ODDONE, N. Cooperación transfronteriza en América Latina: una aproximación teórica al escenario centroamericano desde la experiencia del Proyecto Fronteras Abiertas. Oikos, Rio de Janeiro, v. 13, n. 2, 2014.

PAES DE PAULA, A. P. Por uma nova gestão pública: limites e potencialidades da experiência contemporânea. Rio de Janeiro: FGV, 2005.

PREUSS, L. T. Territórios fronteiriços e os processos de integração regional no Mercosul. In: Seminário Estadual de Estudos Territoriais e II Jornada de Pesquisadores sobre a Questão Agrária no Paraná. Paraná. Anais...Paraná, 2014.

PRADO, H. S. de A. A Cooperação Descentralizada no Mercosul e a Política de Fronteira do Brasil. In: PRADO, Henrique Sartori de Almeida; NETO Tomaz Espósito (Org.) Fronteiras e relações internacionais. Curitiba: Ithala, 2015.

RÜCKERT, A. A.; CARNEIRO FILHO, C. P.; UEBEL, R. R. G. Cenários de Transfronteirizações na América do Sul: alguns exemplos de pesquisas recentes. Revista GeoPantanal, UFMS/AGB, Corumbá/MS, n.18, p.159-181, 2015.

SADECK, B. R. V.; BARROS, P. S. A Política Externa Brasileira e as Fronteiras no Processo de Integração da América do Sul. Boletim de Economia e Política Internacional, BEPI, n. 22, Jan./Abr., 2016.

SANT'ANNA, F. M. O Papel da Integração Fronteiriça para a Integração Regional na América Latina. REVISTA GEONORTE, Edição Especial 3, v.7, n.1, p.1169-1185, 2013.

SCHMITTER, P. C. "Neo-neo-functionalism". In: WIENER, A. e DIEZ, T. (eds.). European integration theory. Oxford: Oxford University Press, 2003.

SCHEIBE, E. F. Integração física e integração regional: a Iniciativa para Integração da Infraestrutura Regional Sul-Americana (IIRSA) como instrumento multiescalar de integração. Dissertação (Mestrado). Programa de Pós-Graduação em Geografia da UFRGS. Porto Alegre: IGEO/UFRGS, 2013. 
SENHORAS, E. M. Múltiplas Camadas das Relações Internacionais entre a Diplomacia e a Paradiplomacia. Revista Intellector, Rio de Janeiro, v.9, n.18, Janeiro/Junho, 2013.

STEIMAN, R.; MACHADO, L. O. Limites e Fronteiras internacionais: uma discussão históricogeográfica. Rio de Janeiro, UFRJ, 2002.

TENORIO, F. G.; SARAIVA, E. Escorços sobre gestão pública e gestão social. Ijuí: Ed. Unijuí, 2007.

THOMPSON, J. B. Ideologia e cultura moderna: teoria social crítica na era dos meios de comunicação de massa. Rio de Janeiro: Vozes, 1995.

UNILA, Universidade Federal da Integração Latino-Americana. Disponível em http://www.unila.edu.br/. Acesso em: jun. de 2021.

Veronese, M. V. \& GUARESCHI, P. A. Hermenêutica de Profundidade na Pesquisa Social. Ciências Sociais. Unisinos, p.85-93, 2006.

VIGEVANI, T.; FAVARON, G. de M.; JÚNIOR, H. R.; CORREIA, R. A. O papel da integração regional para o Brasil: universalismo, soberania e percepção das elites. Revista Brasileira de Política Internacional. p.5-27, 2008. 